\title{
Chronic thromboembolic pulmonary hypertension: time for research in pathophysiology to catch up with developments in treatment
}

\author{
Mark Toshner* and Joanna Pepke-Zaba*
}

Address: Papworth Hospital, Papworth Everard, Cambridge, CB23 3RE, UK

*The contribution of these two authors is equal.

Corresponding author: Joanna Pepke-Zaba (joanna.pepkezaba@papworth.nhs.uk)

Fl000Prime Reports 2014, 6:38 (doi:10.12703/P6-38)

All F1000Prime Reports articles are distributed under the terms of the Creative Commons Attribution-Non Commercial License (http://creativecommons.org/licenses/by-nc/3.0/legalcode), which permits non-commercial use, distribution, and reproduction in any medium, provided the original work is properly cited.

The electronic version of this article is the complete one and can be found at: http://f $1000 . c o m / p r i m e /$ reports $/ \mathrm{m} / 6 / 38$

\begin{abstract}
The modern treatment era in chronic thromboembolic disease has seen significant advances in both surgical and medical treatment. One such treatment, the pulmonary endarterectomy (where established chronic organized thrombus is removed), has dramatically affected morbidity and mortality. These advances have outstripped basic research into the causes and pathophysiology of disease, which remain largely poorly understood. In this review, we will set out to explain some of the historical reasons for this, including the difficulties inherent in human studies and the lack of good animal models. We will review some of the recent advances in pathophysiology from registries and translational research, and we will summarize the treatment options, with some discussion of very recently published work, including medical and surgical treatments, both traditional and more experimental work in non-invasive techniques.
\end{abstract}

\section{Introduction}

Chronic thromboembolic pulmonary hypertension $(\mathrm{CTEPH})$ represents the consequences of failure of thrombus resolution after the establishment of thrombosis within the elastic pulmonary arteries. Thrombotic material becomes fibrosed, with occlusive vascular remodeling and the development of a secondary small vessel arteriopathy, termed the two-compartment model [1], and a resultant increase in pressure and vascular resistance in the pulmonary vasculature. This leads eventually to right heart failure. Pathologically, within the organized thrombus, there is deposition of matrix, mixed cellularity and variable small vessel recanalization (Figure 1). There is heterogeneity of all of these processes in specimens from pulmonary endarterectomy [2], partly depending on the freshness of thrombus. The angiogenesis or neovascularization seen within the thrombus is not to be confused with bronchial collateralization (which also occurs in CTEPH), and depends on the vasa vasorum of the systemic bronchial arteries. There are, however, suggestions that the ability to neovascularize the thrombus may influence the clinical course in animal models, as described more fully in a recent review [3] and discussed later.

CTEPH was first recognized as a potential consequence of pulmonary emboli as far back as the 1920s [4] but has only gained prominence in the last 15 years after the advent of potentially curative surgical techniques. With greater awareness of the disease, it is being more widely recognized, with estimates following an episode of acute pulmonary embolus ranging from 0.8 to $8 \%$ in autopsy series, US healthcare insurance databases, and retrospective and prospective studies [5-10]. To put this into perspective, this would mean a prevalence of between 11 and 109 per million cases. These estimates do not take into account the rates of cases presenting with no acute pulmonary embolus, which can range anywhere from 25 to $63 \%$ of all cases with CTEPH [11-13]. The advent of the pulmonary endarterectomy, pioneered by Jamieson and his colleagues in San Diego [14], has sharpened attention on this orphan disease, with significant improvements in both mortality and morbidity. Despite the added 
Figure I. Macroscopic image of specimen from pulmonary endarterectomy

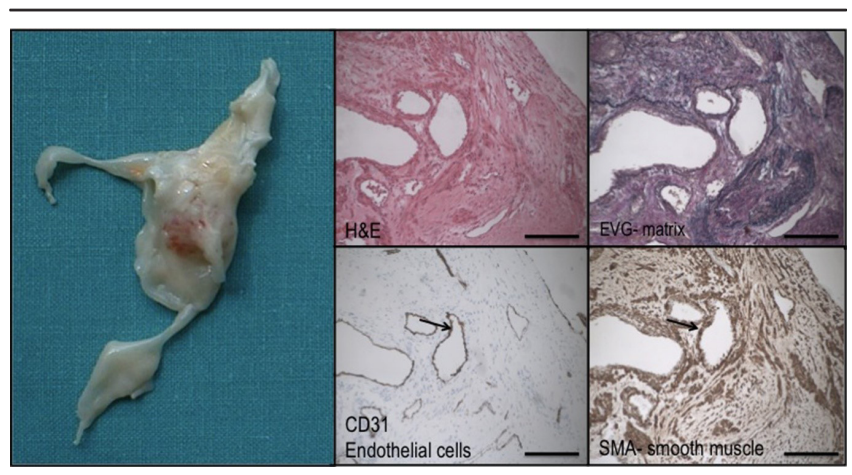

Microscopic organised thrombus from established distal tail of specimen with matrix deposition, endothelial channels and smooth muscle cells/ myofibroblasts distributed throughout the specimen. Scale bar $=100 \mu \mathrm{m}$. Abbreviations: H\&E, haematoxylin and eosin staining; EVG, elastic van Gieson staining (black = elastin, red = collagen; SMA, smooth muscle actin).

focus this has provided, our understanding of the pathobiology has not progressed in parallel. This review will clarify current understanding of disease pathophysiology, introduce the difficulties of relevant animal and human models and discuss exciting new treatment developments, both in medical and surgical management.

\section{Pathophysiology: what are the problems?}

The process of coagulation and fibrinolysis is well-studied and summarized elsewhere extensively $[15,16]$. Despite this, we still do not understand what happens when these pathways fail. There are two critical barriers in human studies. The first is studying the right patients at the right time. As discussed earlier, although estimates vary, between 0.5 and 8 in 100 patients with acute pulmonary embolus will develop CTEPH. Therefore, to capture the relevant phase of their disease (where clot resolution is failing) would require the screening of very large numbers of patients from presentation. The second factor is equally important: the simple inability to study patients off anticoagulation. Almost all patients will be treated with anticoagulation drugs and this makes the interpretation of the major pathways of thrombus formation and resolution technically very challenging. By definition, CTEPH will not be diagnosed unless there is chronic evidence of disease on anti-coagulation (usually for a period of 3-6 months) [17]. Therefore, it is difficult to interpret coagulation and fibrinolysis pathways in this context.

\section{Does more thrombus form?}

Despite the difficulties in studying patients, some surprising findings are made apparent from demographic analyses.
The many known factors associated with thrombosis are not uniformly associated with CTEPH. For example, the classical risk factors for recurrent thrombosis, such as antithrombin deficiency, protein $\mathrm{C}$ and $\mathrm{S}$, prothrombin mutations and factor $\mathrm{V}$ Leiden, are not independently associated with CTEPH [13]. In other words, factors that increase the risk of thrombosis will be present in the CTEPH population but not necessarily more than in populations of patients with deep vein thrombosis (DVT) or pulmonary emboli. There are, however, several risk factors emerging robustly from international registries. These include iatrogenic physical causes of thrombus, such as ventriculoarterial shunts, and indwelling venous catheters and leads. Other important risk factors include inflammatory bowel disease, non-O blood group, malignancy, splenectomy and thyroid replacement [13].

Despite the lack of association of some traditional thrombotic risk factors, there is evidence of a prothrombotic milieu. Plasma concentrations of factor VIII and von Willebrand Factor, which circulate bound to each other, are increased in CTEPH [18]. In 122 patients with CTEPH, levels were significantly elevated $(233+/-83 I U /$ $\mathrm{dL})$ vs. healthy controls $(123+/-40 \mathrm{IU} / \mathrm{dL})$ and a disease comparator group of other pulmonary arterial hypertension ([PAH] 158+/-61IU/dL). Of note, this study did not compare levels to the obvious disease control of patients with resolved pulmonary emboli, but the levels were potentially biologically significant. The elevated levels of von Willebrand Factor persisted after a successful pulmonary endarterectomy, suggesting more than a bystander role in the context of established thromboembolism. In addition to a prothrombotic milieu, some groups are also contending that there is an, as yet, unclearly delineated role for inflammation. The C-reactive protein has been noted to be elevated in CTEPH vs. healthy controls (4.9 vs. $2.3 \mathrm{mg}$ ) and weakly correlates with New York Heart Association measures of disease severity and 6-minute walk distance [19]. It has been suggested that tumor necrosis factor (TNF) and interleukin-6 are increased, though compared to post-pulmonary endarterectomy sampling and not controls [20], and monocyte chemoattractant protein-1 has also been found to be correlated to hemodynamics in CTEPH (though in this study TNF was not) [21]. This study also did not compare to a control group, describing in-group correlations. Related to inflammation, it has been suggested that chronic infection is associated with CTEPH. However, the best evidence is observational in ventriculoarterial shunts and pacemaker lines associated with CTEPH, where DNA from Staphylococcus aureus was found in explanted tissue from pulmonary endarterectomy in patients already suspected of having chronic infection [22]. Given that this 
is a small sub-group of patients with CTEPH, and the possible contribution of low-level chronic inflammation rather than the infection primarily, it is difficult to be clear on the relevance of these findings.

\section{Is thrombus resolution significantly impaired?}

Impaired fibrinolysis is the next obvious area for study. Plasminogen activator inhibitor-1, an inhibitor of fibrinolysis, is increased in endothelial cells lining fresh thrombus in conjunction with low tissue-type plasminogen activator antigen levels, suggesting that the endothelium interaction with thrombus may be phenotypically altered [23]. Myofibroblasts postulated to be potential multipotent mesenchymal progenitors are a prominent feature of established thrombus and it is not yet clear if they have a positive or negative effect in fibrotic repair/ misrepair [24]. Morris et al. demonstrated a relative resistance of patient fibrin to plasmin-mediated lysis in patients with CTEPH, though the effect was modest [25]. We have previously demonstrated a potential genetic susceptibility with an increase in the fibrinogen $A \alpha$ Thr312Ala polymorphism in CTEPH (35.5\%) vs. normal controls $(27.5 \%, P=0.03)$ [26]. This has subsequently been confirmed in a Chinese population where they additionally demonstrated an increase when compared to a patient cohort of pulmonary embolus [27]. This polymorphism has been demonstrated to modify fibrin structure in clots with increased alpha chain cross-linking [28]. Subsequently, Morris et al. have gone on to show that in a small cohort of 33 patients with CTEPH, five fibrinogen variants with corresponding heterozygous gene mutations were observed: $\mathrm{B} \beta \mathrm{P} 235 \mathrm{~L} / \gamma \mathrm{R} 375 \mathrm{~W}$, $\mathrm{B} \beta$

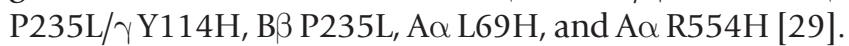
Further extending this work, they have demonstrated that, compared to normal fibrinogen, CTEPH-associated dysfibrinogenemias exhibited fibrinolytic resistance [30]. It does, therefore, appear that mutations in fibrinogen have a potential causative role, though their impact has not yet been fully established.

\section{Are these problems not amenable to animal modeling?}

Although acute embolism is not difficult to mimic or induce, thrombus resolution has proven intractable to model accurately. This is perhaps unsurprising given the relative low frequency in human studies. Models have focused on trying to replicate the physiology of disease. The traditional reliance on lower cost murine models has significantly hampered this. For example, pathologically, CTEPH will often involve significant bronchial collateralization, but the mouse does not have a collateral circulation. Fibrinolytic pathways vary in animal models [31], and there is the additional problem of the two-compartment model. This model is generally accepted and states that, in addition to an obstructed vascular bed, there is a second "compartment" of unobstructed vasculature, subject to increased flow, high pressures, shear stress and the development of small vessel changes typical in other forms of pulmonary hypertension [1]. Some features, such as plexiform lesions, have been difficult to model across all pulmonary hypertension animal models, not just CTEPH. The most recent attempt to resolve some of these issues used a piglet model with a left pulmonary artery ligation and weekly embolization with Histoacryl, a tissue adhesive [31]. This achieved a good medium-term increase in pulmonary vascular resistance (PVR) with significant pulmonary vascular remodeling. This will be useful in assessing therapies and right ventricular remodeling, but not in understanding pathogenesis. An example of how animal models may help pathophysiology was very recently published looking at splenectomies in mice [32]. Well established (as discussed earlier) as a risk factor, this was modeled in mice, where a splenectomy was combined with stagnant flow mimicking DVT. Larger and more persistent thrombus was linked to an increase in circulating microparticles and negatively charged phospholipids [32]. The stagnant flow model has also been used very recently to try to understand the contribution of impaired neovascularization to disease progression, with endothelial cell-specific deletion of $K d r$ and stagnant venous flow, perhaps not unexpectedly influencing thrombus resolution [33]. The contribution of the endothelial cell itself to both the impaired resolution of thrombus and neoangiogenesis is poorly understood and could be addressed using mouse models. We do know from human studies that pulmonary artery endothelial cells from CTEPH patients may be subtly different with, for example, different responses to mitogenic stimuli in vitro [34], and the cellular origins of some of the endothelial channels have been called into question with the demonstration of CD133+ve endothelial cells in the neovessels [35].

How do the pulmonary circuit and heart adapt? The right ventricle undergoes a process of "left ventricularization" in response to increased afterload as assessed by conductance catheter pressure volume loops [36]. Interestingly, this can be seen even without the development of pulmonary hypertension, in patients with significant chronic thromboembolic disease and pulmonary artery pressures $<25 \mathrm{mmHg}$. Increased resistance, decreased compliance and hence increased afterload contribute to diastolic, as well as systolic, dysfunction. This process, in the context of CTEPH, is potentially reversible with some reverse remodeling demonstrated after pulmonary endarterectomy [37]. There is some debate about whether these 
relationships are fixed through the spectrum of diseases causing pulmonary hypertension but, in proximal operable CTEPH at least, it appears that decreased compliance can be demonstrated, potentially putting an extra burden on the right ventricle [38]. With increased awareness of $\mathrm{CTEPH}$, the field is recognizing an increasing proportion of patients with chronic thromboembolic disease without $\mathrm{PAH}$, and as yet it is not clear if these patients are being picked up earlier in their disease process (and have, therefore, not developed PAH/right ventricle dysfunction), or if they are adapting better for as yet unknown reasons. This area is fertile for future research and may provide insights into the differences in right ventricle adaptation.

\section{Treatment: a surgical success story}

Without question, the major success in CTEPH has been the development of the pulmonary endarterectomy. Mortality rates have come down, with the best centers now routinely describing rates comparable to more commonly undertaken cardiothoracic procedures, and most series will demonstrate reductions in PVR in the region of 400-500 dyn $\cdot \mathrm{sec} \cdot \mathrm{cm}^{-5}$ [39-41]. San Diego, the most experienced world center with the largest historical cohort reports on an in-hospital mortality rate now down to $2.2 \%$. At our center, contemporaneous in-hospital mortality is $2-3 \%$ [42]. These compare favorably with improvements made with medical therapy in other pulmonary hypertension disease classes, and long-term survival at 5 years in experienced centers is around $90 \%$. The symptomatic improvements seen are maintained in a long-term follow-up [39-41]. Therefore, despite the initial controversy of the operation, the undoubted institutional learning curve required, and the high mortality rates in the early days, the pulmonary endarterectomy has established itself as the gold standard in CTEPH treatment. It has unequivocally proven that, despite the two-compartment model suggesting that thrombus removal alone would not abolish disease, curative treatment is a possibility if resistance comes down enough. This is an important lesson for the other causes of pulmonary hypertension.

Despite the success of the pulmonary endarterectomy, not all patients are suitable for surgical intervention. This is predominantly related to the distal, surgically inaccessible distribution of thrombus, and additional co-morbidities. Medical therapies have, so far, been less successful in this group. The broad success of the vasodilation therapeutic strategy in group I PAH has not been as convincingly replicated in CTEPH. Despite initially promising openlabel studies, the first double-blinded randomized control trials (RCT) in sildenafil and bosentan were equivocal, using the traditional endpoints of the 6-minute walk distance and hemodynamics $[43,44]$. There is a debate around the correct endpoints for pulmonary hypertension, but this is outside the scope of this review. For clarity purposes, the trials in class $1 \mathrm{PAH}$ single therapies were generally positive using these endpoints and are directly comparable. Last year, however, the first definitively positive large-scale trial was reported with a novel compound, riociguat, which targets pulmonary vasodilation through soluble guanyl cyclase stimulation. The CHEST-1 double-blinded RCT in 261 patients with inoperable and post-operative residual disease reported a 6-minute walk distance improvement of $39 \mathrm{~m}$, compared with a decrease of $6 \mathrm{~m}$ in the placebo group (95\% confidence interval, 25 to $67 ; P<0.001)$. PVR decreased by $226 \mathrm{dyn} \cdot \mathrm{sec} \cdot \mathrm{cm}^{-5}$ compared with a decrease of $23 \mathrm{dyn} \cdot \mathrm{sec} \cdot \mathrm{cm}^{-5}$ in the placebo group $(95 \%$ confidence interval, -303 to $-190 ; P<0.001)$. It is still not clear why the more traditional and established vasodilators were apparently less successful in CTEPH, though caution is needed in overinterpreting a small sample size of only two RCTs.

Surgery, therefore, is well established, and medical therapy is establishing a role in inoperable disease. More controversial is the emergence of less-invasive operative techniques. The first reported case series of balloon angioplasty was in 2001 by Feinstein and his colleagues in Boston [45]. The technique met with initial skepticism, and was not repeated in more than sporadic cases, until 2012 [46]. A series of case studies, predominantly from Japan [47-50], have now confirmed that balloon angioplasty is feasible and potentially results in significant lowering of PVR and improvements in morbidity, though there is variation in both endpoints and results. However, there are some significant caveats to the interpretation of this work. Firstly, although the stated intention of the majority of these studies was to trial inoperable CTEPH, it is clear from some of the reporting that patients were included who would have been deemed operable in other centers. For example, Sugimura et al. [48] report 12 cases where the mean segmental procedure was 14 , which would definitely be deemed technically operable by most specialist centers. In addition, the lack of well-developed pulmonary endarterectomy services has been a significant driver of this innovation, meaning the assessment for operability is in the hands of less experienced operators. The procedures are long, involve multiple visits (an average of three-four), high doses of radiation, significant rates of reperfusion injury and the additional risk of pulmonary dissection. Despite these caveats, we feel it is likely that angioplasty has a role, and careful multi-center randomized trials with well-phenotyped and -characterized patients are now needed. 


\section{Conclusions}

The international visibility of СТЕPH has never been higher, driven largely by innovations in treatment. Research in pathophysiology is lagging significantly behind, partly for technical reasons. It is likely that a better understanding of the pathophysiology will help identify at-risk patients, changing the treatment paradigm to a preventative strategy. As yet this remains only an aspiration, and will not impact on the significant population who do not present with acute venous thromboembolism. Although traditionally viewed as a rare disease, CTEPH is actually not an uncommon complication of a common disease, and these authors think that the advent of large-scale registries, efforts to improve animal models and affordable genome-wide screening tools will see the uncovering of novel contributors to pathophysiology. Until then, the pulmonary endarterectomy leads the way as a treatment paradigm and demonstrates that pathophysiology can be reverse remodeled, with important lessons for consideration across the pulmonary hypertension disease spectrum.

\section{Abbreviations}

CTEPH, chronic thromboembolic pulmonary hypertension; DVT, deep vein thrombosis; PAH, pulmonary aterial hypertension; PVR, pulmonary vascular resistance; TNF, tumor necrosis factor; RCT, randomized control trials.

\section{Disclosures}

The authors declare that they have no disclosures.

\section{References}

I. Moser KM, Bloor CM: Pulmonary vascular lesions occurring in patients with chronic major vessel thromboembolic pulmonary hypertension. Chest 1993, 103:685-92.

2. Yi ES, Kim H, Ahn H, Strother J, Morris T, Masliah E, Hansen LA, Park K, Friedman PJ: Distribution of obstructive intimal lesions and their cellular phenotypes in chronic pulmonary hypertension. A morphometric and immunohistochemical study Am J Respir Crit Care Med 2000, 162:1577-86.

3. Lang IM, Pesavento R, Bonderman D, Yuan JX: Risk factors and basic mechanisms of chronic thromboembolic pulmonary hypertension: a current understanding. Eur Respir J 2013, 41:462-8.

4. Barnes AR, Yater WM: Failure of right ventricle due to ancient thrombus in the pulmonary arteries. M Clin North America 1929, 12.

5. Pengo $\mathrm{V}$, Lensing, Anthonie WA, Prins $\mathrm{MH}$, Marchiori A, Davidson BL, Tiozzo F, Albanese P, Biasiolo A, Pegoraro C, lliceto S, Prandoni P: Incidence of chronic thromboembolic pulmonary hypertension after pulmonary embolism. N Engl J Med 2004, 350:2257-64.

6. Ribeiro $A$, Lindmarker $P$, Johnsson $H$, Juhlin-Dannfelt $A$, Jorfeldt $L$ : Pulmonary embolism: one-year follow-up with echocardiography doppler and five-year survival analysis. Circulation 1999 , 99: 1325-30.

7. Becattini C, Agnelli G, Pesavento R, Silingardi M, Poggio R, Taliani MR, Ageno W: Incidence of chronic thromboembolic pulmonary hypertension after a first episode of pulmonary embolism. Chest 2006, 130:172-5.

8. Miniati M, Monti S, Bottai M, Scoscia E, Bauleo C, Tonelli L, Dainelli A, Giuntini C: Survival and restoration of pulmonary perfusion in a long-term follow-up of patients after acute pulmonary embolism. Medicine (Baltimore) 2006, 85:253-62.

9. Martí D, Gómez V, Escobar C, Wagner C, Zamarro C, Sánchez D, Sam A, Briongos S, Gaudó J, Sueiro A, Jiménez D: Incidencia de hipertensión pulmonar tromboembólica crónica sintomática y asintomática. Arch Bronconeumol 2010, 46:628-33.

10. Klok FA, Zondag W, van Kralingen, Klaas W, van Dijk, Arie PJ, Tamsma JT, Heyning FH, Vliegen HW, Huisman MV: Patient outcomes after acute pulmonary embolism. A pooled survival analysis of different adverse events Am J Respir Crit Care Med 2010, 18 I:50 I-6.

II. Bonderman D, Jakowitsch J, Adlbrecht C, Schemper M, Kyrle PA, Schönauer V, Exner M, Klepetko W, Kneussl MP, Maurer G, Lang I: Medical conditions increasing the risk of chronic thromboembolic pulmonary hypertension. Thromb Haemost 2005, 93:5 I2-6.

12. Condliffe R, Kiely DG, Gibbs JSR, Corris PA, Peacock AJ, Jenkins DP, Goldsmith K, Coghlan JG Pepke-Zaba J: Prognostic and aetiological factors in chronic thromboembolic pulmonary hypertension. Eur Respir J 2009, 33:332-8.

13. Pepke-Zaba J, Delcroix M, Lang I, Mayer E, Jansa P, Ambroz D, Treacy C, D'Armini AM, Morsolini M, Snijder R, Bresser P, Torbicki A, Kristensen B, Lewczuk J, Simkova I, Barberà JA, Perrot M de, Hoeper MM, Gaine S, Speich R, Gomez-Sanchez MA, Kovacs G, Hamid AM, Jaïs $X$, Simonneau G: Chronic thromboembolic pulmonary hypertension (CTEPH): results from an international prospective registry. Circulation 20I I, I24:1973-8I.

14. Jamieson SW, Auger WR, Fedullo PF, Channick RN, Kriett JM, Tarazi RY, Moser KM: Experience and results with 150 pulmonary thromboendarterectomy operations over a 29-month period. J Thorac Cardiovasc Surg 1993, 106: I 16-26; discussion 126-7.

\section{FlOOOPrime}

15. Gailani $D$, Renné $T$ : The intrinsic pathway of coagulation: a target for treating thromboembolic disease? J Thromb Haemost 2007, 5:1106-12.

16. Mackman N, Tilley RE, Key NS: Role of the extrinsic pathway of blood coagulation in hemostasis and thrombosis. Arterioscler Thromb Vasc Biol 2007, 27:1687-93.

17. Kim NH, Delcroix M, Jenkins DP, Channick R, Dartevelle P, Jansa $P$, Lang I, Madani MM, Ogino H, Pengo V, Mayer E: Chronic thromboembolic pulmonary hypertension. J Am Coll Cardiol 2013, 62:D92-9.

18. Bonderman $D$, Turecek PL, Jakowitsch J, Weltermann A, Adlbrecht C, Schneider B, Kneussl M, Rubin LJ, Kyrle PA, Klepetko W, Maurer G, Lang IM: High prevalence of elevated clotting factor VIII in chronic thromboembolic pulmonary hypertension. Thromb Haemost 2003, 90:372-6.

FIOOOPrime

19. Quarck R, Nawrot T, Meyns B, Delcroix M: C-reactive protein: a new predictor of adverse outcome in pulmonary arterial hypertension. J Am Coll Cardiol 2009, 53:12II-8.

20. Langer F, Schramm R, Bauer M, Tscholl D, Kunihara T, Schäfers H: Cytokine response to pulmonary thromboendarterectomy. Chest 2004, 126:|35-41.

21. Kimura H, Okada O, Tanabe N, Tanaka Y, Terai M, Takiguchi Y, Masuda M, Nakajima N, Hiroshima K, Inadera H, Matsushima $K$, Kuriyama T: Plasma monocyte chemoattractant protein-I and pulmonary vascular resistance in chronic thromboembolic pulmonary hypertension. Am J Respir Crit Care Med 200I, 164:319-24.

22. Bonderman D, Jakowitsch J, Redwan B, Bergmeister H, Renner M, Panzenböck H, Adlbrecht C, Georgopoulos A, Klepetko W, KneussI M, Lang IM: Role for staphylococci in misguided thrombus resolution of chronic thromboembolic pulmonary hypertension. Arterioscler Thromb Vasc Biol 2008, 28:678-84. 
23. Lang IM, Marsh J], Olman MA, Moser KM, Loskutoff DJ, Schleef RR: Expression of type I plasminogen activator inhibitor in chronic pulmonary thromboemboli. Circulation 1994, 89:27I5-21.

\section{FIOOOPrime}

\section{RECOMMENDED}

24. Firth AL, Yao W, Ogawa A, Madani MM, Lin GY, Yuan JX: Multipotent mesenchymal progenitor cells are present in endarterectomized tissues from patients with chronic thromboembolic pulmonary hypertension. Am Physiol J Cell Physiol 2010, 298: Cl217-25.

\section{FloOOPrime}

RECOMMENDED

25. Morris TA, Marsh J], Chiles PG, Auger WR, Fedullo PF, Woods VL: Fibrin derived from patients with chronic thromboembolic pulmonary hypertension is resistant to lysis. Am J Respir Crit Care Med 2006, I 73: 1270-5.

\section{FlOOOPrime
RECOMMENDED}

26. Suntharalingam J, Goldsmith K, van Marion V, Long L, Treacy CM, Dudbridge F, Toshner MR, Pepke-Zaba J, Eikenboom, JCJ, Morrell NW: Fibrinogen Aalpha Thr3 I2Ala polymorphism is associated with chronic thromboembolic pulmonary hypertension. Eur Respir J 2008, 31:736-4I.

27. Li J, Lin Y, Yang Y, Gan H, Liang Y, Liu J, Yang S, Zhang W, Cui N, Zhao L, Zhai Z, Wang J, Wang C: Fibrinogen A $\alpha$ Thr3I2Ala polymorphism specifically contributes to chronic thromboembolic pulmonary hypertension by increasing fibrin resistance. PLOS ONE 2013, 8:e69635.

\section{FlOOOPrime}

\section{RECOMMENDED}

28. Standeven KF, Grant PJ, Carter AM, Scheiner T, Weisel JW, Ariëns, Robert AS: Functional analysis of the fibrinogen Aalpha Thr3 I 2Ala polymorphism: effects on fibrin structure and function. Circulation 2003, 107:2326-30.

\section{FlOOOPrime RECOMMENDED}

29. Morris TA, Marsh JJ, Chiles PG, Magaña MM, Liang N, Soler X, Desantis DJ, Ngo D, Woods VL: High prevalence of dysfibrinogenemia among patients with chronic thromboembolic pulmonary hypertension. Blood 2009, I I 4: 1929-36.

\section{FIOOOPrime}

30. Marsh JJ, Chiles PG, Liang N, Morris TA: Chronic thromboembolic pulmonary hypertension-associated dysfibrinogenemias exhibit disorganized fibrin structure. Thromb Res 2013, 132:729-34.

\section{FlOOOPrime}

\section{RECOMMENDED}

31. Mercier O, Fadel E: Chronic thromboembolic pulmonary hypertension: animal models. Eur Respir J 2013, 41:1200-6.

32. Frey MK, Alias S, Winter MP, Redwan B, Stübiger G, Panzenboeck A, Alimohammadi A, Bonderman D, Jakowitsch J, Bergmeister $H$, Bochkov V, Preissner KT, Lang IM: Splenectomy is modifying the vascular remodeling of thrombosis. J Am Heart Assoc 2014, 3:e000772.

33. Alias S, Redwan B, Panzenböck A, Winter MP, Schubert U, Voswinckel R, Frey MK, Jakowitsch J, Alimohammadi A, Hobohm L, Mangold A, Bergmeister H, Sibilia M, Wagner EF, Mayer E, Klepetko W, Hölzenbein TJ, Preissner KT, Lang IM: Defective angiogenesis delays thrombus resolution: a potential pathogenetic mechanism underlying chronic thromboembolic pulmonary hypertension. Arterioscler Thromb Vasc Biol 2014, 34:810-9.

34. Quarck R, Wynants M, Ronisz A, Sepulveda MR, Wuytack F, van Raemdonck D, Meyns B, Delcroix M: Characterization of proximal pulmonary arterial cells from chronic thromboembolic pulmonary hypertension patients. Respir Res 2012, 13:27.

\section{FlOOOPrime}

35. Yao W, Firth AL, Sacks RS, Ogawa A, Auger WR, Fedullo PF, Madani MM, Lin GY, Sakakibara N, Thistlethwaite PA, Jamieson SW, Rubin LJ, Yuan JX: Identification of putative endothelial progenitor cells (CD34+CD I33+Flk-I+) in endarterectomized tissue of patients with chronic thromboembolic pulmonary hypertension. Am J Physiol Lung Cell Mol Physiol 2009, 296:L870-8.

36. McCabe C, White PA, Hoole SP, Axell RG, Priest AN, Gopalan D, Taboada D, MacKenzie Ross R, Morrell NW, Shapiro LM, PepkeZaba J: Right ventricular dysfunction in chronic thromboembolic obstruction of the pulmonary artery: a pressure-volume study using the conductance catheter. J Appl Physiol 2014, I 16:355-63.

37. Reesink HJ, Marcus JT, Tulevski II, Jamieson S, Kloek JJ, Vonk Noordegraaf $A$, Bresser P: Reverse right ventricular remodeling after pulmonary endarterectomy in patients with chronic thromboembolic pulmonary hypertension: utility of magnetic resonance imaging to demonstrate restoration of the right ventricle. J Thorac Cardiovasc Surg 2007, 133:58-64.

38. MacKenzie Ross, Robert V, Toshner MR, Soon E, Naeije R, Pepke-Zaba J: Decreased time constant of the pulmonary circulation in chronic thromboembolic pulmonary hypertension. Am J Physiol Heart Circ Physiol 2013 305:H259-64.

39. Freed DH, Thomson BM, Tsui, Steven S L, Dunning JJ, Sheares KK, Pepke-Zaba J, Jenkins DP: Functional and haemodynamic outcome I year after pulmonary thromboendarterectomy. Eur J Cardiothorac Surg 2008, 34:525-9; discussion 529-30.

40. Madani MM, Auger WR, Pretorius V, Sakakibara N, Kerr KM, Kim NH, Fedullo PF, Jamieson SW: Pulmonary endarterectomy: recent changes in a single institution's experience of more than 2,700 patients. Ann Thorac Surg 2012, 94:97-103; discussion 103.

\section{FlOOOPrime
RECOMMENDED}

4I. Mayer E, Jenkins D, Lindner J, D’Armini A, Kloek J, Meyns B, Ilkjaer LB, Klepetko W, Delcroix M, Lang I, Pepke-Zaba J, Simonneau G, Dartevelle P: Surgical management and outcome of patients with chronic thromboembolic pulmonary hypertension: results from an international prospective registry. J Thorac Cardiovasc Surg 201 I, 141:702-10.

\section{FlOOOPrime
RECOMMENDED}

42. National Pulmonary Hypertension Audit 2012 report. Health and Social Care Information Centre (HSClC); 2013. [http://www. hscic.gov.uk/searchcatalogue?productid = | 1350 \&infotype $=0 \% 2 \mathrm{FAu}-$ dit\&sort $=$ Most + recent\&size $=50$ \&page $=1]$

43. Suntharalingam J, Treacy CM, Doughty NJ, Goldsmith K, Soon E, Toshner MR, Sheares KK, Hughes R, Morrell NW, Pepke-Zaba J: Long-term use of sildenafil in inoperable chronic thromboembolic pulmonary hypertension. Chest 2008, 134:229-36.

44. Jaïs $X$, D'Armini AM, Jansa P, Torbicki A, Delcroix M, Ghofrani HA, Hoeper MM, Lang IM, Mayer E, Pepke-Zaba J, Perchenet L, Morganti A, Simonneau G, Rubin LJ: Bosentan for treatment of inoperable chronic thromboembolic pulmonary hypertension: BENEFiT (Bosentan Effects in iNopErable Forms of chronlc Thromboembolic pulmonary hypertension), a randomized, placebocontrolled trial. J Am Coll Cardiol 2008, 52:2 I27-34.

45. Feinstein JA, Goldhaber SZ, Lock JE, Ferndandes SM, Landzberg MJ: Balloon pulmonary angioplasty for treatment of chronic thromboembolic pulmonary hypertension. Circulation 200I, 103:10-3.

46. Kataoka $M$, Inami $T$, Hayashida $K$, Shimura $N$, Ishiguro $H$, Abe $T$, Tamura Y, Ando M, Fukuda K, Yoshino H, Satoh T: Percutaneous transluminal pulmonary angioplasty for the treatment of chronic thromboembolic pulmonary hypertension. Circ Cardiovasc Interv 20I2, 5:756-62. 
47. Mizoguchi $\mathrm{H}$, Ogawa $\mathrm{A}$, Munemasa $\mathrm{M}$, Mikouchi $\mathrm{H}$, Ito $\mathrm{H}$, Matsubara $H$ : Refined balloon pulmonary angioplasty for inoperable patients with chronic thromboembolic pulmonary hypertension. Circ Cardiovasc Interv 2012, 5:748-55.

\section{FlOOOPrime \\ RECOMMENDED}

48. Sugimura K, Fukumoto $Y$, Satoh K, Nochioka K, Miura Y, Aoki T, Tatebe S, Miyamichi-Yamamoto S, Shimokawa H: Percutaneous transluminal pulmonary angioplasty markedly improves pulmonary hemodynamics and long-term prognosis in patients with chronic thromboembolic pulmonary hypertension. Circ J 2012, 76:485-8.

FlOOOPrime

RECOMMENDED
49. Andreassen AK, Ragnarsson A, Gude E, Geiran O, Andersen R: Balloon pulmonary angioplasty in patients with inoperable chronic thromboembolic pulmonary hypertension. Heart 20I3, 99:14I5-20.

\section{FlOOPrime}

RECOMMENDED

50. Inami T, Kataoka M, Shimura N, Ishiguro $H$, Yanagisawa R, Taguchi $H$, Fukuda K, Yoshino H, Satoh T: Pulmonary edema predictive scoring index (PEPSI), a new index to predict risk of reperfusion pulmonary edema and improvement of hemodynamics in percutaneous transluminal pulmonary angioplasty. JACC Cardiovasc Interv 2013, 6:725-36.

FlOOOPrime

RECOMMENDED 